University of Nebraska - Lincoln

DigitalCommons@University of Nebraska - Lincoln

Industrial and Management Systems

Industrial and Management Systems

Engineering Faculty Publications

Engineering

1995

\title{
Simulation Project Characteristics in Industrial Settings
}

\author{
Paul Savory \\ University of Nebraska at Lincoln, psavory2@gmail.com
}

Follow this and additional works at: https://digitalcommons.unl.edu/imsefacpub

Part of the Industrial Engineering Commons, Operational Research Commons, and the Other Operations Research, Systems Engineering and Industrial Engineering Commons

Savory, Paul, "Simulation Project Characteristics in Industrial Settings" (1995). Industrial and Management Systems Engineering Faculty Publications. 48.

https://digitalcommons.unl.edu/imsefacpub/48

This Article is brought to you for free and open access by the Industrial and Management Systems Engineering at DigitalCommons@University of Nebraska - Lincoln. It has been accepted for inclusion in Industrial and Management Systems Engineering Faculty Publications by an authorized administrator of DigitalCommons@University of Nebraska - Lincoln. 


\section{Simulation Project Characteristics in Industrial}

Settings

JEFFERY K. COCIIRAN

Gerald T. Mackulak
PaUl A. SAvory

Systems Simulation Lahoratory

Industrial and Management Systems Engine Arizona State University

Tempe, Arizoma 85287-5906

Systems Simulation Laburatory

Industrial and Manage'me'nt Systems Enginecrinty Arizona State University

Industrial and Management Systems Enginecring University of Nebrask

Lincoln, Nebraska 68588-0518

In a survey of practitioners of discrete-event simulation from industry and research institutes who "build models for money," we asked about project goals, user backgrounds and training, organizational types and activities, software and hardware choices, modeling team composition, and effort allocation within a modeling project. We found that (1) only about half of the practitioners have three or more years experience, (2) many academics feel strongly affiliated with their industry clients rather than with their university employers, (3) shop-floor supervisors rarely lead simulation projects, even though their knowledge of the system may be unparalleled, (4) simulation models are generally described as unique custom models, yet practitioners indicate that they commonly build similar models, (5) although simulators (parameter-driven simulation environments that require no user coding) are now available, few respondents indicate using any simulators for simulation projects.

Simulation is one of industry's most used operations research techniques [Lane, Mansour, and Harper 1993]. Its uses range from answering questions about work-in-process and production feasibility

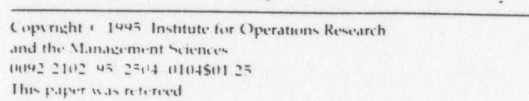

to comparing alternative plans for system routing and scheduling. Yet, in spite of (or perhaps because of ) its broad user base, opinions about its efficacy as an industrial decision support tool vary greatly. Horror SIMLLATION-APP'LACAIIONS
TROFESSIONAL-SLRLES stories are as numerous as success stories. Many authors [Dietz 1992; Law 1986; Pegden et al. 1990; Sadowski 1989; These and Travis 1988; and Ulgen 1991] have written about simulation methodology. Here at the Systems Simulation Laborato (SSL) at Arizona State University, our studies are leading us to believe that successful simulation practice is more dependent on methodology than on software tools.

As part of a funded research project for the National Institute of Standards and Technology and the Institute for Manufacturing and Automation Research, we developed and administered a questionnaire [Cochran, Manathkar, and Mackulak 1993] to practitioners in a wide range of industrial settings. Surveys on simulation are not unusual. Industrial Engineering magazine [Torrey, July 1992, p. 43, and Torrey, May 1993, p. 10] reports the results from fax surveys on simulation and its role in an industrial engineer's job. Unfortunately, these surveys provide only limited insight on how simulation is practiced on the job. A decade ago, Christy and Watson [1983] published results similar to ours for a sample of nonacademic simulation users. Many of their issues remain pertinent, but they did not collect data on the composition of simulation teams and the effort allocation within them. Furthermore, since their study, computer hardware and simulation software have changed. Our objectives in writing this paper are to inform Interfaces readers about current simulation practices in industrial settings, describe how those practices have changed over the past decade, and focus on the skill set of the individual practitioner now at work in

A copy of our questionnaire is available by mail from the SSL. The questionnaire i four pages long and consists of 27 yuestions. Questions are multiple choice, and space is provided to allow participants to write in nonstandard responses. From presurvey studies, we estimate that it takes about 10 minutes to complete the ques. tionnaire. The questions are grouped into the following categories:

- The user's background and training in simulation,

- How the user's emplover uses simulation,

- The characteristics of a typical modeling project, and

- How effort is allocated in a simulation project.

We stored and analyzed the results from the survey using the PARADOX database software from Borland International.

Survey Participants and Respondents

We targeted a small group of active sim ulation practitioners. We did not send the survey to random organizations, individuals, or universities. Rather, we solicited input from simulation practitioners in industry, research institutes, simulation consulting organizations, and United States simulation funding agencies who have "built models for money." We sent the questionnaire electronically and by mail to a sample of SCS (Society for Computer Simulation) members, Svstem Simulation Laboratory industrial and academic contacts, and all subscribers of Simulation Digest (an electronic simulation newsletter posted to the USENET news group: comp.simulation.misc). 
We received a total of 138 survey responses from individuals in 11 countries. Of the 400 surveys mailed, 95 were returned for a response rate of around 24 percent. We received an additional 43 re sponses from readers of the Simulation Di gest in which we had included the survey. Since people can receive the Simulation $D$ gest by many different methods, we cannot compute a response rate for that publication. We did not receive all the responses at the same time. We used a follow-up strategy that allowed us to verify that the initial nonrespondents did not differ statistically from respondents. We, therefore, have a good level of confidence that our results represent the behavior of the target population (subject, obviously, to samplin error).

The survey respondents are a mixture of industrial practitioners, academics, simula tion consultants, and others who use simu lation in a variety of fields (for example, manufacturing, airlines, postal services, research laboratories, and service comp nies). The specific responses by job classifcations are industry ( 48 percent), academia (46 percent), and government (six percent). We have analyzed the responses both by individual job classification and by combining all classifications. Except in a few

\begin{tabular}{lr} 
Years & Percent \\
\hline 3 or more & $56 \%$ \\
2 to 3 & $9 \%$ \\
1 to 2 & $15 \%$ \\
1 or less & $20 \%$
\end{tabular}

Table 1: Survey respondents indicate that over half have three or more years of simulation experience.
Table 2: The primary source of simulation raining was university instruction.

cases, there are no significant differences among the results. To simplify our prese tation, we will present combined results and will highlight any differences that vides. Let us turn our attention now to th survey results.

Only about half of the practitioners have three or more years of experience (Table 1). When asked about their primary method of obtaining training in simulation (Table 2), 58 percent learned at a university, while the next largest percentage $(23$ percent) learned in an industrial seminar. Eight percent indicate that they have no formal education in simulation!

The practitioners exhibit a wide range of past experience (Table 3). Twenty-five percent have participated in more than 15 projects, while more than a third have participated in fewer than five.

Number of Projects Percent

\section{Less than 5} $36 \%$ Between 5 and 10 Between 10 and 15

$$
\text { More than } 15
$$
brocendent group includes prac titioners who have participated in over 15 projects (25 percent) as well as those who have been involved in under five projects (36 percent).
Education and Research

Project

Mass production line

Batch production

Job shop

Continuous flow line

Other

Table 4: The primary business activities of the respondents' organizations cover a range of application areas.

Organizational Use of Simulation We asked the practitioners to identify their primary business activity (Table 4 ). The seven business activity categories in our survey are education and research (teaching, writing publications, for exam ple, university), project (custom-made products, quantity of one, for example shipbuilding, space vehicles), mass produc tion line (high volume, discrete production similar products, for example, automobiles, toys), batch production (medium volume, periodic batches, for example, chemicals, industrial equipment), job shop (low volume, small batches of products, for example, machine tool shops, commercial printing), continuous flow line (high volume continuous production, for example, oil re-

\begin{tabular}{lcccc} 
Simulation Project Goal & $\begin{array}{l}3 \text { Years or } \\
\text { More }\end{array}$ & $\begin{array}{l}2 \text { to } 3 \\
\text { Years }\end{array}$ & $\begin{array}{l}1 \text { to } 2 \\
\text { Years }\end{array}$ & $\begin{array}{l}1 \text { Year or } \\
\text { Less }\end{array}$ \\
\hline Design & $23 \%$ & $23 \%$ & $22 \%$ & $21 \%$ \\
Research & $23 \%$ & $17 \%$ & $20 \%$ & $26 \%$ \\
Scheduling & $19 \%$ & $23 \%$ & $21 \%$ & $14 \%$ \\
Planning & $16 \%$ & $17 \%$ & $15 \%$ & $18 \%$ \\
Assignments and allocation & $15 \%$ & $17 \%$ & $22 \%$ & $12 \%$ \\
Other & $4 \%$ & $3 \%$ & $0 \%$ & $9 \%$
\end{tabular}

Table 5: A breakout of simulation project goals compared to years of practitioner simulation experience shows no significant variation.

mills), and other. Although almost half of the responses we received came from academics, only 33 percent of the participants reported their primary business activity to be education and research. It seems that many academ ics who "build models for money" feel strongly affiliated with their industrial clients rather than with their university emplovers.

The other production activities reported are diverse and include project-oriented activities (17 percent), mass production lines (14 percent), batch production (nine percent), and continuous flow line (five percent). A combined 15 percent (no one tallying more than two percent) are in areas other than those we specified, of which the largest two are software development and transportation modeling. Sim ulation is indeed widely used.

Within differing business activities, common goals for a simulation project are evident (Table 5). The most common goal is design (facility design, system development and design). Next is research (product development, industry modeling), followed by scheduling (shop floor work-flow analysis, priorities, and due dates). A mod-
erate use of simulation is reported for
INTERFACES 25:4 
planning (forecasting, analysis of marketing strategies, consumer behavior prediction) and also for assignment and allocation problems (personnel analysis, resourc allocation, personnel scheduling). Other uses of simulation reported include testing scientific theory, studying health care svstems, modeling weapon svstems, and ana lyzing data. A separate analysis by job classification reveals that industry's top goals are slightly different-design and planning. In a separate study [Ozdemirel, Mackulak, and Cochran 1993], we review gave a detailed breakdown of simulation project goals.

The level of experience among practition ers tackling a given goal is also shown in Table 5. Experience levels are not uniformly distributed over simulation project goals; however, the differences are not statistically significant. That is, people of equal skill are addressing each of these goals in industry.

Although companies are thought to readily hire people with simulation skills on a consultant basis, about 30 percent of 6) that they know of no obstacles to per-

Obstacle Percent

\section{No obstacles}

Lack technical backgroun

Need for dedicated personnel

Training

Cost

Other

$30 \%$

Table 6: There are not always obstacles to performing simulation in-house. When obs cles exist, they are primarily related to a shortage of experienced personnel. published simulation modeling papers and the practitioners surveyed indicated (Table
Table 7: The leader of a simulation team is ypically a systems analyst or developer, de spite the fact that the shop-floor supervisor may know the system best.

forming simulation in-house. Obstacles to in-house simulation analysis identified in clude lack of technical background (21 percent), need for dedicated personnel (15 percent), training ( 12 percent), and cost ( 10 percent). Additional obstacles include lack of management support and inadequate time for development.

Identifying the best leader for a simulation team is not a well-understood decision. Currently the majority of team leaders are simulation specialists and svstems analysts (Table 7)

Characteristics of a Typical Modeling Project

The frequency of use of simulation within an organization varies widely. Many respondents ( 39 percent) build simu lation models weekly (Figure 1), while some (18 percent) use simulation on a yearly basis. Simulation models are generally described as being unique, custom modeling tasks, but practitioners indicate that they commonly build similar models. At the SSL, we have pursued the intriguing idea of finding generic models and svstematically using them as the basis for model construction [Mackulak and Cochran 1990; Lung et al. 1994].

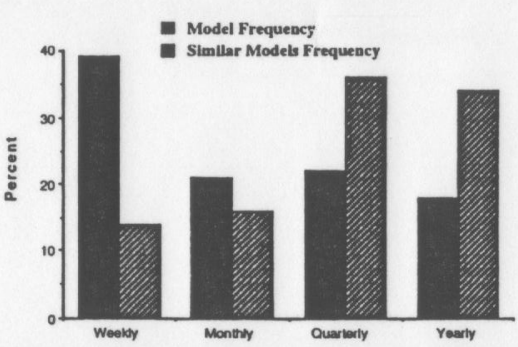

igure 1: Frequency of industry use of simuation varies widely, but similar problems are commonly modeled.

Because analysts often develop similar models, we asked participants how they view reusing parts or even entire models. Five percent describe this task as very easy, 24 percent conclude it is easy, 27 percent say it is difficult, and two percent say it is very difficult. Around 33 percent were neutral on this question, but only nine percent indicated that they never reuse models.

Typically it takes one to three months to complete a simulation project (Table 8 . The majority reported that the average person-effort required to complete a promonths.

A simulation project can be described in

\begin{tabular}{|c|c|c|c|c|c|}
\hline & $\begin{array}{l}1 \text { Week or } \\
\text { Less }\end{array}$ & $\begin{array}{l}1 \text { Week to } \\
1 \text { Month }\end{array}$ & $\begin{array}{l}1 \text { to } 3 \\
\text { Months }\end{array}$ & $\begin{array}{l}3 \text { to } 6 \\
\text { Months }\end{array}$ & $\begin{array}{l}\text { More than } \\
6 \text { Months }\end{array}$ \\
\hline Minimum time for a project & $49 \%$ & $25 \%$ & $13 \%$ & $6 \%$ & $7 \%$ \\
\hline Average time for a project & $4 \%$ & $20 \%$ & $31 \%$ & $16 \%$ & $29 \%$ \\
\hline Maximum time for a project & $0 \%$ & $4 \%$ & $15 \%$ & $16 \%$ & $65 \%$ \\
\hline Person-effort to complete a project & $6 \%$ & $36 \%$ & $29 \%$ & $13 \%$ & $16 \%$ \\
\hline
\end{tabular}

Table 8: Simulation projects take less than a week at a minimum, to more than six months at a maximum. Most projects take between one week and three months average person-effort.

July-August 1995

terms of the language used to develop the model (Table 9). The use of a general proramming language for model development continues. In fact, only 18 percent of the respondents do not use a general purpose programming language. Although Christy and Watson do not report the use of $C$ in their 1983 survey, it is now equal to FORTRAN in its use. Academics some dustry interest present for PASCAL in our sample.

In addition, most practitioners also use a general purpose simulation language because general simulation languages offer many advantages. Of the general purpose simulation languages, SLAM and SIMAN are the most popular among our survey target audience in the production and service industries. Industry participants reported a higher use of SIMAN, and academic participants reported a higher use of SLAM.

Although simulators (parameter-driven simulation environments that require no user coding) have been developed and re leased in recent years, only 40 percent of respondents indicated using any simulators for simulation projects. The most popular is ProModel. Because it relates to our work at the SSL, we asked if participants had
109 ject is over one week but less than three times use PASCAL, but there is little in- 


\begin{tabular}{lrlllr}
$\begin{array}{l}\text { General Purpose } \\
\text { Languages }\end{array}$ & \multicolumn{3}{l}{$\begin{array}{l}\text { General Purpose } \\
\text { Simulation Languages }\end{array}$} & Special Purpose Simulators \\
\hline C & $28 \%$ & SLAMI II & $28 \%$ & PROMODEL & $14 \%$ \\
FORTRAN & $27 \%$ & SIMAN & $28 \%$ & SIMFACTORY & $8 \%$ \\
PASCAL & $7 \%$ & GPSS & $11 \%$ & FACTOR & $4 \%$ \\
BASIC & $6 \%$ & SIMSCRIPT & $6 \%$ & WITNESS & $2 \%$ \\
LISP & $4 \%$ & Other & $11 \%$ & Other & $12 \%$ \\
Other & $10 \%$ & None & $16 \%$ & None & $60 \%$ \\
None & $18 \%$ & & & &
\end{tabular}

These preferences correspond to our findings that personal computers and workstations are the top hardware platforms. Allocation of Effort in a Simulation Project simulation projects, we used the 10 phases of a simulation study defined in Pritsker [1986, p. 10]. We asked respondents to rank each phase on a scale of one to five, where one is the easiest and five is the most difficult (Table 12). They indicate that problem formulation is the most difficult simulation phase ( 3.73 out of five), closely followed by data acquisition (3.56), validation (3.44), and model building (3.30)

surprising that most respondents now run Although respondents indicate that the simulation packages primarily on personal use of OS/2 is increasing. DOS (and Wincomputers and workstations (Table 10). In analyzing the responses by job classification, we found that industry's use of mainframes is small compared to that of universities. Few industry modeling projects use mainframes. This could help explain the higher use of SLAM by universities and of SIMAN in industry. SIMAN was originally

Computer Hardware

Personal computer

Workstation

Mainframe

Mini-computer

dows) for personal computers and UNIX

(used on workstations) remain the most

preferred operating systems (Table 11).

Operating System Percent

\section{DOS}

UNIX

OS $/ 2$
VAX

Macintosh

CMS

MVS

Other

$29 \%$

Table 11: The responses concerning the computer operating systems used for puter operating systems used for simulation pertaining to hardware presponses

Table 10: The computer hardware simulation projects is now dominated by personal computers and workstations.

INTERFACES 25:4
To estimate how effort is allocated in

We also asked our practitioners to divide total project effort among the simulation phases. Respondents estimate that data acquisition is the most time-consuming activity, requiring almost 15 percent of tota project effort. The next most time-

consuming phases are problem formulation model translation, and model build

ing.

For each phase of the simulation process, we asked practitioners to estimate the percentage of that phase that is computerassisted. They reported that the most computer-intensive tasks are experimentation. model translation, and verification. Suftware developers should note that although problem formulation uses 13.80 percent of the project's effort and was rated the most difficult phase, it receives only about nine percent of assistance from the computer.

This is clearly an area in which

development work must occur.

\section{Conclusions}

Sadowski [1989] savs that "the art of modeling is best learned through experience." In our survey of simulation practi tioners and researchers who "build models for money," we sought to tap their combined experience to assess current simulation practices, observe changes, and iden tify trends for the future.

Advances in computer hardware and

\begin{tabular}{lccc} 
Phase of a Simulation Project & $\begin{array}{c}\text { Difficulty } \\
(1 \text { to 5) }\end{array}$ & Time & \multicolumn{1}{c}{$\begin{array}{l}\text { Computer- } \\
\text { Assist }\end{array}$} \\
\hline Problem formulation & 3.73 & $13.80 \%$ & $9.07 \%$ \\
Model building & 3.30 & $10.94 \%$ & $23.98 \%$ \\
Data acquisition & 3.56 & $14.75 \%$ & $36.93 \%$ \\
Model translation & 2.37 & $13.87 \%$ & $62.66 \%$ \\
Verification & 2.74 & $8.15 \%$ & $61.80 \%$ \\
Validation & 3.44 & $8.18 \%$ & $47.35 \%$ \\
Strategic and tactical planning & 2.91 & $6.61 \%$ & $26.92 \%$ \\
Experimentation & 1.84 & $7.55 \%$ & $83.11 \%$ \\
Analysis of results & 2.98 & $9.04 \%$ & $45.00 \%$ \\
Implementation and documentation & 2.59 & $7.11 \%$ & $42.51 \%$
\end{tabular}

Implementation and documentation

Table 12: In estimating effort allocation in a typical simulation project, respondents rated the difficulty of each phase on a scale of one to five, where one is easiest and five is most difficult. They also estimated the percentage of effort (time) each phase consumes of the total project effort (the percentages in this column total 100 percent). In the Computer-Assist column, they
estimated the current percentage of computer assistance in each phase of a simulation project. 


\section{COCHRAN, MACKULAK, SAVORY}

software caused the most changes in the past decade:

(1) The $C$ programming language has achieved the same level of use as FORTRAN

(2) The use of general purpose programming languages for simulation is decreasing.

(3) SIMAN and SLAM are currently the most used simulation languages.

(4) Industry uses mostly PCs rather than mainframe computers.

(5) The use of simulators (ProModel, Witness, and so forth) is slowly increasing. What does the future hold? Christy and Watson [1983], perhaps wisely, did not venture an opinion in these pages 10 years ago, but we have a few ideas. Simulation languages may experience a fate similar to general programming languages, with sim ulators taking their place. Banks, Aviles, McLaughlin, and Yuan [1991] agree that while the current generation of simulators has disadvantages, these limitations will shrink in future software releases. Main frames and FORTRAN may finally disappear. Opportunities for consulting may die out as simulation tools incorporate proper methodology. Libraries of preprogrammed simulation models or reusable modules may become available. In a software market saturated with products, new product development must focus more on the practitioner's needs, such as built-in training. Finally, we hope that the results of our survey aid decision makers in planning. staffing, and managing simulation projects Acknowledgments

We thank the National Institute of Standards and Technology and the Institute of Manufacturing and Automation Research

\section{SIMULATION PROJECTS}

for support in funding this study. We also thank the editors and an anonymous ref eree for suggestions that improved earlier drafts.

\section{References}

anks, Jerry; Aviles, Eduardo; McLaughlin, James R.; and Yuan, Robert C. 1991. "The simulator: New member of the simulation Aamily, Interfaces, Vol. 21, No. 2 (MarchApril), pp. 76-86.

"The application and Watson, Hugh J. 1983, industry practice." simulation: A survey of industry practice," Interfaces, Vol. 13, No. 5
(October), pp. 47-52 Cochran, Jeffery $\mathrm{K}$. $\mathrm{Ma}$

Machan, Jeffery K.; Manathkar, Umesh G.; and Mackulak, Gerald T. 1993, "Multi-level software beta testing: An IntellisIM case study," Business Management and MIS, Sam Dition in California (January) and MIS, Sa

Dietz, Mike 1992, "Outline of a succesf ulation project," Simulation, Vol. 24 pp. 50-53.

Lane, Michael S.; Mansour, Ali H.; and Harper, John L. 1993, "Operations research techniques: A longitudinal update 1973-1988, Interfaces, Vol. 23, No. 2 (March-April), 63-68.

Law. Averill M. 1986, "Introduction to simula. tion: A powerful tool for analyzing complex manufacturing systems," Industrial Engineering. Vol. 18, No. 5, pp. 46-63.

Lung. C. H.; Cuchran, leffery K.; Mackulak, Gerald T.; and Urban, Joseph E. 1994, "Computer simulation software reuse by generic/ specific domain modeling approach," InternaKitmal Tournal of Soffware Engineering and Knowledge Engineering, Vol. 4, No. 1, pp. 81-

Mackulak, Gerald T. and Cochran, Jeffery K. 1990, "Generic/specific modeling: An imOptimization of Mamulation techniques," in D. Shunk D. $237-260$.. Nort Pp. $237-260$.

Comirel, Nur E.; Mackulak, Gerald T.; and Coch classification K. 1993, "A group technolcrete manution and coding scheme for disternational lournal of Production Rodes,
31, No. 3, pp. 579-601.

Pegden, C. Dennis; Shannon, Robert E.; and Sadowski, Randall P. 1990, Introduction to Simulation Using SIMAN, McGraw Hill, New York.

Pritsker, Alan A. B. 1986, Introduction to Simulation and Slam II, Systems Publishing Corporation, West Lafayette, Indiana.

Sadowski, Randall 1989, "The simulation process: Avoiding the problems and pitfalls," Procedings of the 1989 Winter Simulation Conference, Washington DC (December), pp. 7279.

Thesen, Arne and Travis, Laurel 1988, "Introduction to simulation," Proceedings of the 1988 Winter Simulation Conference, pp. 7-14 rorrey, Eric E.. ed. 1992, "Simulation/survey results, "Thdustrial Engimeering, Vol. 24, No. 7 (July), p. 43.

Torrey, Eric E., ed. 1993, "Simulation FAX survey results," Industrial Engineering, Vol. 25 No. 5 (May), p. 10

Jigen, O. M. 1991, "Proper management techniques are keys to a successful simulation

4. pp. 37-41. 